\title{
PELATIHAN ANGKLUNG BAGI KAUM IBU LANSIA DI YAYASAN SOKA GAKKAI MEDAN
}

\author{
Rema Yuni Deswita \\ Pendidikan Musik
}

\begin{abstract}
Rema Yuni Deswita Br. Karo Sekali, NIM: 209342055, Angklung Training For Elderly Mother in Soka Gakkai Foundation Medan. Essay. Faculty of Language and Arts, State University of Medan. Supervisor: (1) Esra PT Siburian, M. Sn, (2) Adina Sastra Sembiring,M.Pd.

This study aims to determine how the role of mother angklung for the elderly in the foundation Soka Gakkai field through the angklung training process. The approach used in this research is descriptive and qualitative. Descriptive approach is used to focus on the actual problem as they are at the time of research training at the foundation Soka Gakkai angklung underway.

Qualitative approach used to describe the problem in training activities angklung in foundation Soka Gakkai. The object of research, namely mothers angklung, Soka Gakkai members, especially in the field of 20 people and 1 coach. This research data collected by direct observation field where research, interviews to several elderly moms and coaches as well as chairman of the association of mothers in the foundation of the Soka Gakkai.

Angklung chosen by the mother Elderly Foundation Soka Gakkai Indonesia on the grounds of Angklung is a musical instrument that is a heritage native Indonesia. Simple musical instrument made of bamboo which was originally a musical instrument played to war but thanks to the cold hands of the father Angklung Daeng Soetigna transformed into a musical instrument that has a diatonic tones world standard that can be used in all the song's accompaniment.

Practicing music is also useful for the health of the elderly, taken from the title of this paper researchers believe that playing angklung useful to stimulate the motion system of the elderly who have fallen and psychology useful for the elderly. By having groups that perform activities together would be very useful for the Elderly psychologyinordernottofeellonely.
\end{abstract}

Kata Kunci: Training, Musical Instruments Angklung, Elderly

\section{PENDAHULUAN}

Angklung merupakan alat musik asli Indonesia yang terbuat dari bambu dan merupakan warisan budaya bangsa Indonesia yang sudah dikenal selama berabad-abad. Angklung juga merupakan alat musik multitonal yang secara tradisional, berkembang dalam masyarakat Sunda di Pulau Jawa bagian barat. Di Jawa Barat angklung digunakan untuk upacara yang berhubungan dengan padi, jadi angklung tidak dijadikan sebagai kesenian mumi 
melainkan sebagai kesenian yang berfungsi dalam kegiatan kepercayaan. Ritual ini masih dilakukan oleh masyarakat pedalaman Sunda seperti suku Badui atau Kanekes di Kabupaten Lebak di Cipining Bogor.

Angklung tidak dapat dipisahkan dari seorang yang bernama Daeng Soetigna seorang guru di Kuningan Jawa Barat yang berhasil mengembangkan angklung dari skala nada pintatonik ke skala nada diatonik kromatik pada tahun 1938, maka untuk menghargai karya beliau angklung bernada diatonis ini kemudian diberi nama angklung Padaeng. Pak Daeng seorang guru yang juga seorang pembina kepandaian yang terilhami oleh seorang pengemis serta bapak Jaya seorang pembuat angklung.

Angklung Padaeng terdiri dari dua kelompok, yaitu angklung melodi dan angklung pengiring. Angklung melodi adalah angklung yang ditujukan untuk memainkan melodi utama dalam suatu lagu. Angklung ini memiliki dua atau lebih tabung suara yang dikombinasikan dengan prinsip oktaf. Kemudian angklung pengiring atau angklung akonpanimen yang bertugas menjadi pengiring lagu, biasanya dimainkan dengan dicentok. Angklung ini memiliki tiga atau lebih tabung suara, yang dikombinasikan dengan prinsip akord.

Pengertian pelatihan berarti membantu pertumbuhan batin tanpa dibatasi oleh usia. Proses pertumbuhan ialah proses menyesuaikan pada tiap-tiap fase serta menambahkan kecakapan dalam perkembangan seseorang.

Angklung Padaeng, pada awalnya diciptakan untuk mengajar Ilmu Seni Musik Barat. Saat masa itu, hal ini merupakan terobosan karena untuk pertama kalinya, alat musik nusantara digunakan untuk menggantikan alat musik Eropa. Alat musik angklung pada dasarnya sangat mudah untuk dimainkan, sehingga alat musik tersebut sangat cocok digunakan untuk mengajarkan ilmu musik dasar.

Sehingga, hal inilah yang membuat semua orang dengan cepat bisa memainkannya tanpa perlu bakat musik yang kuat maupun latihan panjang. Angklung juga merupakan alat musik satu nada yang dapat memudahkan guru atau pengajar mengajarkan konsep nada diatonis. Angklung juga terbagi menjadi dua kelompok yaitu melodi dan akompanimen yang secara langsung mencontohkan teori harmonisasi suara, 
angklung Padaeng juga punya potensi sebagai alat musik konser yang megah dan juga layak dipakai untuk berbagai genre musik.

Potensi yang terdapat pada alat musik angklung tersebut, akhirnya membuat Menteri Pendidikan Kebudayaan Republik Indonesia mengeluarkan peraturan pemerintah yang menetapkan angklung sebagai alat pendidikan musik.

Ungkapkan bahwa potensi yang ada pada angklung, lansia juga dapat dengan mudah mempelajarinya.

Lansia merupakan usia yang sangat rentan pada kesehatan fisik dan mental. Sehingga, banyak orang mengatakan bahwa semakin tua seseorang maka akan semakin menyerupai anak-anak lah orang tersebut, tenaga berkurang, kulit keriput, gigi makin rontok, tulang makin rapuh hingga sulit melakukan ini dan itu, emosi mereka juga tidak terkontrol dengan baik. Setelah seseorang memasuki masa lansia maka ia mengalami penurunan fungsi kognitif meliputi proses belajar, persepsi, pemahaman, pengertian, dan perhatian sehingga menyebabkan reaksi dan perilaku lansia menjadi semakin lambat.
Sementara fungsi psikomotorik meliputi hal-hal yang berhubungan dengan dorongan kehendak seperti gerakan, tindakan, koordinasi yang berakibat bahwa lansia menjadi kurang cekatan.

Akibat berkurangnya fungsi indera pendengaran, penglihatan, gerak fisik dan sebagainya maka muncul gangguan fimgisional atau bahkan kecacatan pada lansia. Misalnya badannya menjadi bungkuk, pendengaran sangat berkurang, penglihatan kabur dan sebagainya sehingga sering menumbulkan keterasingan. Hal itu dapat dicegah dengan selalu melakukan aktifitas, selama yang bersangkutan masih sanggup.

Musik sendiri dapat menjadi terapi bagi lansia untuk melatih kembali fungsi organ tubuh yang melemah seperti pendengaran, penglihatan, dan gerak fisik. Dalam permainan musik angklung inipun terkandung unsur pelatihan bagi semua kalangan terkhusus bagi kaum lansia karena didalam pembelajaran musik angklung terdapat sifat disiplin, tanggung jawab, kerjasama/gotong royong, tahu tugas dan kewajiban, solidaritas, demokrasi, konsentrasi dan etos kerja. Dengan dibentuknya komunitas atau kelompok- 
kelompok musik angklung bagi lansia dapat menjadi suatu aktifitas bagi lansia untuk membangun kembali rasa percaya diri dan mencegah para lansia merasa terasing atau terasingkan.

Soka Gakkai sendiri bermula dari ajaran yang awal nya disebut Nichiren sho shu yang artinya sekte benar Nichiren, didirikan pada tahun 1253 oleh pendeta Nikko, murid pendeta Nichiren. Sekte Nichiren adalah salah satu sekte Buddha yang cukup unik.

Keunikannya adalah sekte ini tidak melakukan penyembahan ke arca Buddha seperti yang umum dilakukan pada tradisi Buddha lainnya. Sebagai gantinya mereka meletakkan Mandara, tulisan atau huruf Jepang yang berisikan mantraatautulisansuciyangdikeramatkan. (NichirenShoshuInternasionalCenter:198 4). Dalam perkembangan selanjutnya ajaran nichiren ini melahirkan sekte atau kelompok baru yang lebih modern dan solid yang disebut Soka Gakkai.

Berkaitan dengan adanya unsur pelatihan dari pusat kegiatan SGI maka Soka Gakkai di Indonesia terkhusus membuat suatu komunitas musik angklung yang terdiri di beberapa daerah di Indonesia seperti di Jakarta, Medan dan Riau. Yang unik dari komunitas musik angklung tersebut ialah mereka beranggotakan masyarakat yang berumur 50 tahun keatas yang kita sebut sebagai lansia. Maka saya mengambil judul "Pelatihan Angklung Bagi Kaum Lansia di Yayasan Soka Gakkai Medan".

\section{METODE PENELITIAN}

Penelitian ini dilaksanakan di Jln. Jalan Bambu II No.90 Kelurahan Kampung Durian Kecamatan Medan Timur Medan Sumatera Utara dan waktu penelitian dilaksanakan pada bulan Januari 2015 sampai bulan Maret 2015. Berkaitan dengan Dalam dalam penelitian ini adalah seluruh kaum ibu lansia di Yayasan Soka Gakkai medan yang berjumlah 20 orang dan 1 orang pelatih. Metode yang digunakan dalam penelitian ini adalah metode kualitatif deskriptif yang tujuannya memberikan uraian atau gambaran tentang suatu masalah yang diteliti. Penelitian deskriptif menyangkut

\section{HASIL PENELITIAN DAN PEMB A HAS A N}

Angklung dipilih oleh Soka

Gakkai Indinesia bukan tanpa alasan. Pada awal dipilihnya alat musik angklung dipakai oleh Soka Gakkai di 
mulai dari diskusi yang digelar oleh presiden ke 5 Negara Indonesia. Dialog yang berisi tentang keindahan-keindahan budaya yang ada di Indonesia dan budaya yang ada di Jepang, keindahan alam yang ada di Indonesia dan juga keindahan alam yang ada di Jepang dan yang terakir ciri khas yang benar-benar asli dari Indonesia maupun di jepang.

Diskusi atau dialog tersebut diadakan di Kemayoran Jakarta pusat dan diiringi oleh tarian-tarian tradisi Indonesia dan diringi sekelompok orang yang bermain angklung. Anak dari Daisaku Ikaeda yang diutus untuk dialog di Indonesia dan Abdulrrahman Wahid merasa bahwa angklung adalah alat musik asli Indonesia.

Masa lansia adalah puncak dari siklus manusia yang ciri-cirinya cenderung mengalami penurunan baik secara fisiologis, psikologis dan social. Lansia adalah kelompok yang paling rentan terhadap permasalahan kesepian,hal ini disebabkan oleh banyak hal antara lain kehilangan pasangan, berpisah dengan anak-anak yang semakin dewasa, kehilangan relasi atau teman sebaya dan lain sebagainya.

Pada dasarnya terdapat beberapa cara untuk mengurangi penghayatan salah satu nya mengikuti kegiatan sosial dan mendengarkan musik. Angklung dipilih oleh yayasan Soka Gakkai juga mempunyai fungsi yang hampir sama dengan fungsi musik yaitu untuk melatih konsentrasi serta fokus dalam suatu hal di kehidupan sehari-hari dan dengan bermain alat musik angklung para ibu lansia juga masih bisa belajar untuk bekerjasama dengan ibu yang lainnya dalam memainkan alat musik angklung maka terjalinlah ikatan kekeluargaan diantara para pemain angklung satu dengan yang lain.

Untuk mendukung kelancaran pelaksanaan proses kegiatan pelatihan angklung, Yayasan Soka Gakkai Medan menyediakan berbagai fasilitas untuk mendukung kegiatan tersebut antara lain perlengkapan angklung yang masih digunakan untuk latihan, namun beberapa alat telah mengalami kerusakan. Akan tetapi kerusakan alat tersebut tidak

menyurutkan minat para ibu-ibu tersebut untuk mengikuti ekstrakurikuler angklung. Kondisi alat musik angklung tersimpan dengan baik kejadian tersebut disebabkan karena ibu di Yayasan Soka Gakkai memiliki ruangan khusus untuk 
menyimpan semua perlengkapan alat musik.

Tujuan adanya kegiatan pelatihan angklung bagi kaum ibu lansia d yayasan Soka Gakkai ter Soka Gakkai dengan alasan agar alat musik angklung tersebut dapat terjaga kelestariannya. Soka Gakkai mempuanyai misi di beberapa aspek yaitu perdamaian, kebudayaan, dan pendidikan, angklung merupakan aspek kebudayaan yang menurut organisasi Agama Budha Nichiren patut dan wajib untuk dilestarikan keberadaannya selain dari pada bahwa kenyataan nya alat musik angklung lah yang para kaum ibu di yayasan Soka Gakkai Indonesia sukai untuk memainkannya. Kaum ibu di Yayasan juga sebenarnya tidak menutup kemungkinan untuk mempelajari alat musik lainnya namun tetap berbasis alat musik asli milik Tanah air Indonesia.

Dalam proses pelatihan angklung di Yayasan Soka Gakkai pelatih menggunakan metode pengajaran dengan cara demontrasi, latihan (drill), dan Teknik Partisipasi peserta. Selama proses latihan berlangsung pelatih bukan berperan sebagai pendidik, karena yang dihadapi bukanlah anak-anak melainkan orang tua atau para ibu-ibu yang sudah mengerti tentang segala pelajaran hidup namun berperan pemberi bantuan kepada ibu-ibu yang belajar angklung.

Proses demontrasi ini dilaksanakan terus menerus sampai pelatih menganggap para anggota angklung benar-benar mampu untuk mengikuti intruksi yang diberikan pelatih, pelatih juga mengajarkan tehniktehnik dalam bermain angklung.

Setelah proses demontrasi selesai pelatih melanjutkan kembali ke pengajaran yang kedua, yaitu latihan, dalam latihan pelatih memberikan beberapa contoh materi lagu yang ringan yang bias dimainkan bersama-sama oleh para kaum ibu Lansia di Yayasan Soka Gakkai.

Setelah proses pemberian pelatihan terhadap anggota angklung dirasa sudah cukup, melakukan evaluasi terhadap anggota angklung dengan cara: (1) pelatih meminta anggota angklung untuk megulang dan memainkan kembali materi yang sudah diajarkan selama proses ekstrakurikuler. Kemudian

(2) pelatih memberikan koreksi kepada anggota angklung terhadap permainan yang belum sempurna menurut pelatih, 
setelah pengkoreksian terhadap permainan selesai,

(3) pelatih membenahi kembali pola permainan anggota angklung yang belum sempurna sampai permainan benar-benar sempurna untuk ikut serta dalam sebuah event.

Upaya memotivasi Kaum Ibu lansia di Yayasan Soka Gakkai Medan dalam mengikuti pelatihan angklung

Setelah melakukan wawancara dengan ketua kaum ibu, peneliti memperoleh beberapa informasi tentang kegiatan pelatihan angklung yang dilakukuan di Yayasan Soka Gakkai Medan. Sebelum proses pelatihan berjalan, kepala sekolah melakukan upaya untuk memberikan arahan kepada para ibu-ibu anggota angklung untuk melakukan doa sebelum latihan dimulai, lalu memberikan arahan kembali supaya dalam berlatih dibutuhkan keseriusan dan fokus. Upaya lain yang dilakukan ketua kaum ibu di Yayasan Soka Gakkai antara lain :

\section{a. Menyediakan fasilitas}

Ketua kaum ibu berupaya dan berusaha menyediakan semua sarana dan fasilitas yang diperlukan dalam proses pelatihan angklung untuk mendukung ibu-ibu lainnya mengikuti kegiatan angklung. Upaya Ketua kaum ibu dalam memotivasi ibu-ibu lain agar tetap mengikuti kegiatan pelatihan angklung adalah memberikan fasilitas sarana dan prasarana yang diperlukan dalam kegiatan pelatihan tersebut, mendatangkan pelatih khusus yang professional dalam bidang angklung. Menyusun jadwal kedatangan pelatih agar kegiatan angklung berjalan dengan efisien.

Setelah kegiatan pelatihan berjalan sesuai jadwal, sesekali ketua kaum ibu mendatangkan pelatih angklung dan pembuat angklung yaitu murid pencipta angklung yang biasa disebut pak daeng yaitu Bapak Obby A. R. Wiramihardja untuk memberikan pelatihan singkat untuk kaum ibu lansia di Yayasan Soka Gakkai medan.

Satu hal lagi yang di lakukan oleh Ibu ketua dan pelatih agar ibu-ibu tetap aktif mengikuti kegiatan pelatihan angklung yaitu memberikan selingan lelucon humor dalam kegiatan latihan, hal ini dilakukan untuk menghindari kejenuhan para anggota angklung dan juga beberapa menit waktu untuk beristirahat. Sehingga kegiatan pelatihan angklung di Yayasan Soka Gakkai 
Medan tetap berjalan sesuai dengan keinginan yang direncanakan.

\section{Upaya pelatih dalam memotivasi}

Tahap pelaksanaan merupakan kegiatan inti dari semua proses latihan. Dengan persiapan yang sungguh-sungguh dan serius dari pelatih, maka kegiatan tersebut dapat berjalan lancar dan dapat memberikan hasil yang optimal. Dalam tahap pelaksanaan pelatihan angklung, diharapkan dalam proses pelatihanya pemain dapat belajar dengan serius, karena dalam tahap inilah saat penting untuk menentukan langkah pelatihan selanjutnya yaitu latihan akhir atau evaluasi. Dalam proses ini pelatih berperan aktif dalam memotivasi pemain agar mampu menampilkan secara maksimal. Jadi, dengan dorongan semangat dari pelatih diharapkan semua pemain bisa menguasai materi dalam tahap pelaksanaan pelatihan inti tersebut.Adapun upaya-upaya yang dilakukan oleh pelatih antara lain: (1) metode pengajaran: proses pengajaran yang dilakukan pelatih dalam menyampaikan materi sangat baik, karena sebelum pelatih memberikan materi dalam bentuk peragaan, terlebih dahulu pelatih menciptakan suasana yang nyaman untuk anggota angklung, kemudian pelatih menyampaikan apa yang akan di pelajari oleh anggota angklung dengan tekhnik yang baik, seperti dengan nada bicara yang lembut dan murah senyum, sehingga anggota angklung dapat menerima materi yang disampaikan oleh pelatih.Kemudian pelatih menjelaskan lagu yang akan dimainkan, kemudian pelatih memberikan gambaran ketukan atau pola dalam memukul alat-alat angklung mengikuti dari melodi lagu yang sudah dicetak dalam partitur besar sebelum proses demontrasi. Setelah pendemontrasian selesai, pelatih mengajak untuk mencoba materi peragaan yang telah disampaikan. Setelah peserta sudah mengetahui dan berulang kali mencoba bentuk pola dari permainan lagu tersebut kemudian pelatih melanjutkan proses pengajaran.(2) Materi pengajaran, materi kegiatan pelatihan angklung yang diberikan oleh pelatih tergantung dari kemajuan dari peserta angklung, contohnya dalam satu tahun para peserta angklung melatih dua lagu yang akan dipertunjukkan di acara pentas budaya , pelatih akan fokus mengajarkan dua lagu tersebut secara bergantian. Durasi 
latihan setiap minggu ada dua jam, maka satu jam pertama akan mempelajari lagu pertama kemudian satu jam berikutnya yang dipelajari adalah lagu ke dua.

\section{Upaya keluarga dalam memotivasi}

Keluarga juga sangat penting peranannya terhadap segala aktivitas dan kegiatan yang dilakukan oleh orang tua di luar rumah. Umur dari seorang lansia tidak banyak melakukan aktifitas seperti di umur produktif, para lansia seharusnya tetap beraktivitas yang teratur, terstruktur dan menyenangkan melalui kegiatan kesenian seperti melukis yang merupakan proses berpikir dan melatih berpikir holistik, lansia juga harus tetap berolahraga, Juga melalui musik yang mempengaruhi pertumbuhan otak dan sebagai stimulus multi sensorik serta perilaku sosial. Para lansia cenderung mengalami dementia atau gejala pikun jika otak tidak terus menerus dilatih. keluarga mendukung ibu-ibu lansia di yayasan Soka Gakkai untuk ikut berlatih angklung. Keluarga mendukung kegiatan pelatihan angklung dengan mengantar dan menjemput ibuibu pergi dan pulang latihan. Bahkan sebagian anak mereka juga ikut menemani ibu-ibu untuk latihan angklung. Para ibu merasa senang bisa berkumpul dengan teman-temannya yang lain untuk berlatih angklung.

Yayasan Soka Gakkai memulai latihan angklung selalu diawali dengan doa, hal itu dilakukan supaya latihan berjalan dengan lancer secara umumnya. Yayasan Soka Gakkai juga melakukan pelatihan angklung selain untuk mengisi kegiatan sehari-hari adalah untuk pagelaran seni yang dilakukan setiap tahunnya di berbagai tempat.

Selama penelitian berlangsung kaum ibu di Yayasan Soka Gakkai latihan untuk festifal budaya yang secara rutin dilakukan setiap tahun oleh Yayasan Soka Gakkai Indonesia bahkan dunia yang kebetulan diadakan di Indonesia yaitu di Jakarta lebih tepatnya di Istora Senayan pada tanggal 12 Oktober 2015 pukul 14.00- 16.00 WIB yaitu festival kebudayaan dan pameran edukatif untuk perdamaian.

Acara festival kebudayaan dan pameran kebudayaan menampilkan berbagai pertunjukan seni antara lain Rampak Bedug, tarian anak-anak, pertunjukkan kolintang, paduan suara 
oleh lansia dan pertunjukkan angklung oleh kaum Ibu Lansia se Indonesia

Festival kebudayaan yang dilakukan oleh Yayasan Soka Gakkai Indonesia ini juga didukung oleh :

1. Kementrian Pemuda dan Olahraga Republik Indonesia

2. Kementrian Agama Republik Indonesia

3. Kementrian dan Pemberdayaan Perempuan dan Perlindungan Anak Republik Indonesia

4. Kementrian Pariwisata dan Ekonomi KreatifRepublik Indonesia

5. Pemerintah Provinsi DKI Jakarta

6. Puan Amal Hayati

7. Lembaga Kebudayaan Betawi (LKB)

8. Pinkan Indonesia

9. Karya Cipta Indonesia

10. Kreasi Wanita Indonesia (KAWAN INDONESIA)

11. Institut Seni Budaya IndonesiaBandung

Festival ini menghadirkan 1750 Performer dari seluruh Indonesiayang menampilkan berbagai pertunjukan kreasi seni yang megah dan kolosal, diantaranya Color Guard, Young Lion Gymnastic, Rampak Beduk, Tarian anak-anak, Angklung, Kolintang,
Paduan Suara dan berbagai tarian tradisional kolosal dari seluruh Indonesia.

Salah satu keunikan festifal kebudayaan ini adalah para pengisi acara yang bukan berasal dari kalangan professional dalam bidang seni. Mereka berasal dari latar belakang seperti mahasiswa-mahasiswi, pegawai, pelayan warung dan took, ibu rumah $\mathrm{t}$ angga, supir truk, pedagang kecil, guru, bahkan para lansia. Mereka tidak dibayar bahkan mengeluarkan biaya sendiri untuk biaya transportasi dan konsumsi selama latihan berbulan-bulan, kostum dan guru.

Melalui festival ini pula Soka Gakkai Indonesia menunjukkan bahwa dengan budaya kita semua satu, tidak ada lagi perbedaan suku, agama dan ras, semua individu dapat bersatu memberikan persembahan terbaik untuk bangsa melalui jerih payah dan perjuangan tanpa kenal lelah. Harapan akan terciptanya perdamaian bukanlah hal yang tidak mungkin jika didasari dengan niat yang tulus untuk kebahagiaan kelak

Acara yang berdurasi kurang lebih dua jam tersebut, mampu menyedot antusias para penonton yang berasal dari berbagai kalangan seperti 
pejabat Negara, menteri, pegawai, veteran Republik Indonesia, undangan, dan umum.

Hasil pelatihan angklung yang dilakukan rutin dilakukan membuahkan hasil yang memuaskan yang pada awalnya kaum ibu lansia diragukan untuk memainkan alat musik angklung namun bisa menampilkan penampilan yang luar biasa pada saat festival berlangsung.

\section{PENUTUP}

Berdasarkan hasil penelitian dan pembahasan yang telah dipaparkan dalam bab IV adalah Yayasan Soka Gakkai merupakan aliran Buddha Nichiren yang berasal dari Jepang dan mempunyai visi dan misi untuk mewujudkan perdamaian dunia baik dalam bidang pendidikan, dan budaya di setiap daerah di belahan dunia.

Soka Gakkai Internasional menyebarkan ajaran Buddha Nichiren ke seluruh dunia berawal dari Jepang menyebar ke India lalu ke China ke Malaysia dan sampai juga di Indonesia.

Dengan visi dan misi yang dianut oleh Soka Gakkai yaitu mewujudkan perdamaian dunia melalui kebudayaan dan pendidikan lalu di setiap daerah yang tersebar ajaran dari Soka Gakkai maka disetiap wilayah akan banyak pagelaran-pagelaran seni yang diadakan oleh yayasan Soka Gakkai Internasional.

Demikian pula di Indonesia Soka Gakkai mempunyai tugas untuk menciptakan perdamaian melalui pendidikan dan kebudayaan. Melalui pendidikan Yayasan Soka Gakkai membangun sekolah-sekolah, melalui kebudayaan Yayasan Soka Gakkai di Indonesia merasa mempunyai tanggung jawab dalam melestarikan alat musik asli dari Indonesia serta melestarikan tariantarian asli dari Indonesia

Dalam bidang kebudayaan yang berpartisipasi bukan hanya orang tua namun pemuda-pemudi juga turut serta mencintai dan melestarikan budaya Indonesia.

Angklung dipilih oleh kaum Ibu Lansia di Yayasan Soka Gakkai Indonesia dengan alasan karena angklung merupakan alat musik asli yang merupakan warisan leluhur Indonesia. Alat musik yang sederhana yang terbuat dari bambu yang pada awalnya merupakan alat musik yang dimainkan untuk peperangan namun berkat tangan dingin dari bapak angklung Daeng Soetigna diubah menjadi alat musik 
diatonis yang mempunyai nada-nada standart dunia yang bisa digunakan dalam mengiringi semua lagu dunia.

Di Yayasan Soka Gakkai sendiri memainkan lagu dengan alat musik angklung yaitu lagu yang berasal dari alat musik angklung berasal yaitu lagu Manuk Dadali dan March Toward the $21^{\text {st }}$ Century yaitu lagu mars dari Soka Gakkai Internasional.

Berlatih musik juga berguna bagi kesehatan lansia, diangkat dari judul skripsi ini peneliti menganggap bahwa bermain angklung berguna untuk menstimulasi system gerak dari lansia yang sudah menurun serta berguna bagi psikologi lansia. Dengan mempunyai kelompok yang melakukan kegiatan bersama-sama akan sangat berguna untuk psikologi Lansia agar tidak merasa kesepian.

Berdasarkan hasil penelitian, saran yang diberikan guna meningkatkan motivasi kaum ibu lansia di Yayasan Soka Gakkai untuk mengikuti pelatihan angklung yaitu:

1. Untuk peserta angklung, agarlebih aktif lagi dalam mengikuti latihan agar hasil bermain angklung lebih meningkat lagi.
2. Untuk Keluarga, agar kiranya mendukung kegiatan kaum ibu lansia dalam berlatih angklung.

3. Untuk Yayasan Soka Gakkai agar kiranya tetap mencintai budaya Indonesia, tidak hanya belajar angklung namun semua kesenian di Indonesia karena di Indonesia banyak kesenian lainnya yang menarik.

4. Untuk Pelatih agar lebih tegas dalam membantu peserta angklung dalam berlatih angklung.

\section{DAFTAR PUSTAKA}

AWI Angklung Web Institut-AWI Home Angklung-Web-Institut.com.

DaisakuIkeda 2013,,Voka Gakkai Internasional, Mengejar Perdamaian, artikel, Jakarta.

Hadari, Nawawi. H, 1983, Metode Penelitian Bidang Sosial, Gajah Mada University Press, Yogyakarta.

H. B. Sutopo, 1980, Merancang Penelitian Kualitatif dalam LIP, IKIP Semarang Press, Semarang. Margono, Drs. S., 2013, Metodologi Penelitian Pendidikan: Komponen MKDK, Jakarta, Rineka Cipta.

Maryeani. 2005. Metode Penelitan Kebudayaan, Bumi Aksara, Jakarta.

Noor, Dr. Juliansyah, 2011, Metodologi Penelitian, Karisma Putra Utama. Pandji, Dewi, 2012, Menembus Dunia 
Lansia, $\quad P T \quad$ Elex Media Komputindo,Kelompok

Gramedia, Jakarta.

Sugiyono, 2008. Metode Penelitian kuantitadfe, Kualitatife, dan R \& D. Bandung: ALFABETA.

Sukardi. 2004. Metodologi Penelitian Kependidikan,Yogyakarta: Bumi Aksara.

Sukmadinata Nana Syaodih Prof. Dr., 2012, Metode Penelitian Pendidikan, PT Remaja Rosdakarya, Bandung.

Universitas Pendidikan Indonesia, 2000, Pedoman Penulisan Karya Ilmiah. (Laporan Buku, Makalah, Skripsi, Tesis, Disertasi), Bandung: UPI.

Notoatmodjo,1991, Pengembangan Sumberdaya Manusia, Rineka Cipta, Jakarta

Candra Dewi, Arisanti.2010.Rancangan Terapi Musik Angklung Untuk
Menurunkan Penghayatan Perasaan Kesepian (Loneliness) Lansia. Universitas Padjajaran:Bandung

Wiramiharja, Obby, A.R., Pasang Surut Angklung, Masyarakat Musik Angklung, MMA.

Wiramiharja, Obby, A.R., 2010, Panduan Bermain Angklung, November, Jakarta.

Wiramiharja, Obby, A.R., Angklung Padaeng MMA, Jakarta. http://blogbahrul.wordpress.com/ 2007/11/28/landasan-teori-kerangkapikir-dan-hipotesis-penelitian

http://kamriantiramli.worldpress.com/20 11/05/16/landasan-teorikerangka-pikir-dan-pengajuanhipotesis 